Volume 10, No.1, January - February 2021

International Journal of Advanced Trends in Computer Science and Engineering

Available Online at http://www.warse.org/IJATCSE/static/pdf/file/ijatcse201012021.pdf

https://doi.org/10.30534/ijatcse/2021/201012021

\title{
Optimizing Bandwidth Allocation in GPON as a Backhaul to Fulfill 5G Latency Requirement
}

\author{
Gunadi Dwi Hantoro ${ }^{1}$, Purnomo S. Priambodo ${ }^{2}$, Gunawan Wibisono ${ }^{3}$ \\ ${ }^{1}$ Department of Electrical Engineering, Universitas Indonesia, Depok, Indonesia, gunadi.dwi@ui.ac.id \\ ${ }^{2}$ Department of Electrical Engineering, Universitas Indonesia, Depok, Indonesia, p.s.priambodo@ieee.org \\ ${ }^{3}$ Department of Electrical Engineering, Universitas Indonesia, Depok, Indonesia, gunawan@eng.ui.ac.id
}

\begin{abstract}
To achieve full deployment of $5 \mathrm{G}$ services, a backhaul network solution is required to connect the central office to the BTS (Base Station). Some of the current alternatives used for backhaul solutions implement Wireless technology (Radio IP) and wire-line (copper and fiber). The use of fiber network can be used with Metro Ethernet or GPON network approach. The focus of GPON is based on the problems encountered when the requirement of latency is fixed at below $5 \mathrm{~ms}$. Based on the findings of this research, in order to meet the $5 \mathrm{G}$ latency requirement of $5 \mathrm{~ms}$, the most suitable capacity allocation is $70 \%$ with average latency combined of upstream and downlink is $2.8 \mathrm{~ms}$. Furthermore, the average optimum bandwidth capacity is $72.10 \%$ and $72.59 \%$ for GPON and XGSPON respectively.
\end{abstract}

Key words : GPON, 5G Backhaul

\section{INTRODUCTION}

Telecommunications is the exchange of information between two or more persons by the use of technology. It has witnessed massive improvements within the last few decades. Initially, voice communications was the paramount channel of communication but data and video communications has gained wide acceptance in recent times. All information are transmitted on the same media for voice, data and video. Consequent upon the reality of this information-driven age the current society lives in, a reliable transmission medium with a large capacity for transmission of various services is required for communication to flow seamlessly. Copper cable is no longer enough to transmit large capacity of information at high speed. Hence, several operators in the industry are seeking to optimize the quality of their services by constructing optical cable infrastructure to the subscriber's home. These Fiber optic cables are efficient because they are capable of transmitting large capacity data at high speed with sufficient bandwidth.
The implementation of fiber optic cable is perfect for long distance backbone communication. Although, the current use of optical cable is not restricted to backbone communication alone, but also the access aspect of the communication chain. The optical cable infrastructure built from central to end-user is referred to as Fiber To The Home (FTTH) network. Gigabit Passive Optical Network (GPON) is the standard device used. The FTTx network architecture is shown in the figure 1.

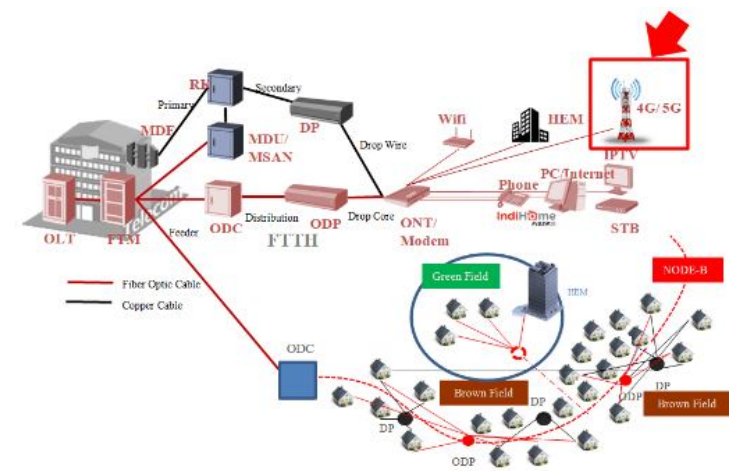

Figure 1 : FTTx Architecture

GPON stands for Gigabit Capable Passive Optical Network. This technology is needed for voice, data and video services. Passive optical network PON or Passive Optical Network is divided into 2: the upstream signal and the downstream signal. Upstream signal is the speed of data flow sent from the user to the service provider, while the downstream signal is the speed of data flow sent from the service provider to the user. Upstream and downstream signals are two signals that have 2 different wavelengths to prevent interference. The PON distribution based on the technology used consists of APON or ATM Passive Optical Network, GEPON or Gigabit Ethernet Passive Optical Network, GPON or Gigabit Capable Passive Optical Network, and EPON or Ethernet Passive Optical Network. GPON technology was developed specifically for fiber-to-the-home (FTTH) due to cost advantages through a point-to-point system. It was developed with ITU-T technology. GPON compared to other technologies has a high bit rate and better market dominance. Backhaul is a term used to define communication lines, specifically microwave/fiber between a base station and a 
communication switch. Its characteristics are providing the use of ultra-high capacity per end on the device as well as providing new services, such as augmented reality. Implementing this requires major infrastructural changes as well as a high capacity wireless backhaul per cell and the expected node density of approximately $50 \mathrm{BS} / \mathrm{km} 2$.

$5 \mathrm{G}$ technology is predicted to have data rates of up to $10 \mathrm{Gbit}$ I s, up from the previous generation. Every technological development requires preparation for implementation both in the preparation of regulations, industry readiness and others. Presently, Indonesia has just entered the 4G technology stage, hence the advent of $5 \mathrm{G}$ technology is a bit distant, even though it cannot be denied that $5 \mathrm{G}$ technology will come whether Indonesia is ready or not.

5G cellular backhaul consists of traditional fronthaul, midhaul, and backhaul. Fronthaul refers to the last mile transportation link that connects RRH to the network. Midhaul is the relationship between the fronthaul aggregation point and the backhaul network. Backhaul links connect BBU to the network. Further, groups of all transportation links are also referred to as backhaul networks.

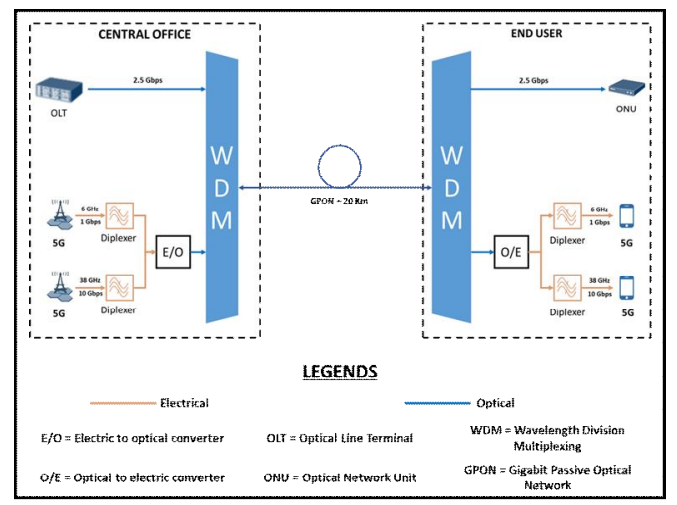

Figure 2 : GPON Block Diagram for 5G Networks

Figure 2 shows a simplified block diagram of a GPON based front-end architecture for a $5 \mathrm{G}$ network. After combining the $5 \mathrm{G}$ signals at 6 and $38 \mathrm{GHz}$ using a diplexer, the signal is converted to an optical signal by applying an electric-to-optical (E/O) converter. Coupler Wavelength Division Multiplexer (WDM) combines the two optical signals carrying the $5 \mathrm{G}$ signal and the $2.5 \mathrm{Gbps}$ baseband signal to the Gigabit-capable Passive Optical Network (GPON). On the remote side, the WDM decoupler performs the reverse process by separating the two initial optical signals.

\section{METHODS AND EXPERIMENT SETUP}

While bandwidth can certainly impact network speed, complaints about lagging or buffering issues are often associated with latency. When a data packet is sent from one location to another, it still needs to physically travel the distance over cables or some form of wireless frequency regardless of the speed of fiber-optic cables used. However, data is still limited by the laws of physics and will never be able to exceed the speed of light. This implies that there will always be an upper limit to how fast data can move through a network even under ideal or non-ideal conditions. While the bulk of the transmission may utilize fast network infrastructure, traversing the "last mile" before reaching either end of the connection often involves a hodge-podge of slower connections that reduce speed significantly.

Latency measures the lag between the moment a data packet is sent and the moment it is received and processed. In the early days of internet connections, latency was rarely an issue because bandwidth limitations masked how slowly data travelled through networks. The delay between requests were generally smaller than the amount of data that could move through the connections, therefore latency was all but invisible. As higher bandwidth connections have greatly increased download speeds, latency has become much more noticeable. For example, an image may only take 5 milliseconds to download, but latency may cause users to wait 100 milliseconds before they receive the first byte of data from their download request.

Bandwidth may not be the primary determinant of speed for many customers but it is nonetheless important to understand how it impacts network performance along with factors like latency and throughput. The relationship may not be direct, but their interaction has an important influence on speed. If a network is plagued by high latency connections, no amount of bandwidth will be sufficient in helping it transfer data. Similarly, driving down latency with edge computing deployments may not deliver improved performance if bandwidth and throughput remain low.

There are several existing methods used to augment the capacity of GPON technology to support 5G backhaul. Among these methods are Dynamic Bandwidth Allocation (DBA) and Network Slicing.

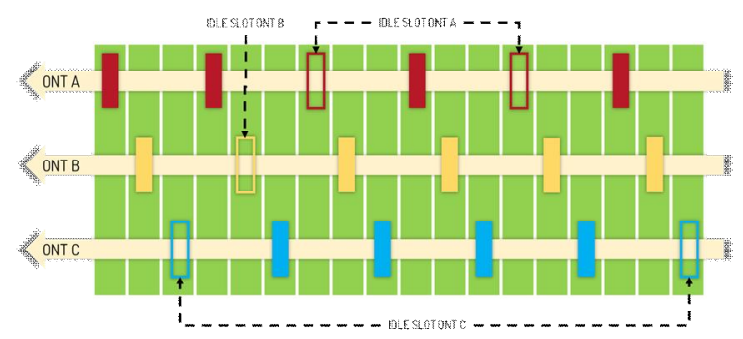

Figure 3 : Example of Static Bandwidth Allocation

DBA is the technique by which traffic bandwidth in a shared telecommunications medium can be allocated on demand and fairly between different users of that bandwidth instead of allocating bandwidth in a fixed manner as seen in figure 3 . This is a form of bandwidth management and is essentially the same thing as statistical multiplexing. It occurs where the sharing of a link adapts in some way to the instantaneous 
traffic demands of the nodes connected to the link. DBA is a mechanism in place to dynamically change upstream BW on a mili-second/micro-second timescale. DBA improves the efficiency of the PON upstream bandwidth by dynamically adjusting the bandwidth among the ONUs in response to ONU burst traffic requirement.

A good DBA algorithm quickly adjusts the upstream bandwidth allocation to the ever-changing traffic scenarios. At any given time slot, sufficient bandwidth are allocated to certain ONTs (or certain services). In other time slots, the bandwidth would be allocated to other ONTs or other services, maximizing utilization of the PON bandwidth. An example of DBA algorithm can be seen in figure 4 .

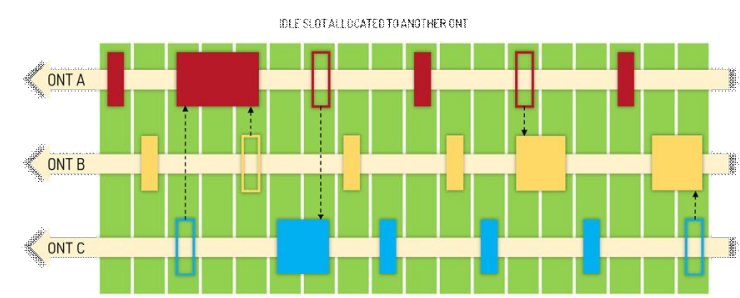

Figure 4 : Example of Dynamic Bandwidth Allocation

In GPON network there are various types of DBA algorithms, mainly Status Reporting DBA (SR-DBA) and Non-Status Reporting DBA (NSR-DBA). Also, the NSR algorithm, the OLT estimates bandwidth allocation for the next DBA cycle required by each T-CONT, on the basis of the bandwidth usage during the previous DBA cycle. At the beginning of each cycle, the OLT assigns assured bandwidth for each T-CONT based on the amount of data transmitted in the previous cycle. After this assignment, the remaining GPON bandwidth is divided between non assured traffic. In the end, the rest of the available bandwidth is distributed to obtain the best traffic.

In the SR scheduling, the OLT requests the buffer occupancy status from each T-CONT, indicating the number of bytes waiting for transmission. At the beginning of a new frame, one T-CONT of each type gets a token. The T-CONT possessing a token is granted allocation slots according to the request, providing that it does not exceed its maximum bandwidth allowed for the current cycle. At first, requests for assured allocations are served and then bandwidth allocations are given to consecutive non-assured bandwidth requests. In the end, best effort requests are served. After each T-CONT is served, the next in order T-CONT receives the token. At the beginning of a new frame, T-CONTs with tokens received in the previous uplink frames are served first.

$5 \mathrm{G}$ service itself has several requirements for it to function optimally. These requirements include the maximum latency requirement of $5 \mathrm{~ms}$ and the ability to utilize high bandwidth requirements. In the PON network, these requirements have been largely ignored due to technological limitations in accommodating maximum latency. For this reason, this study was conducted to analyze the capabilities of the GPON network and the XGSPON network, which are theoretically superior to the PON network, so that it can be used as a backhaul of $5 \mathrm{G}$ services.

Trial tests are carried out using ONT and OLT directly connected to analyze the process delay at the access node.

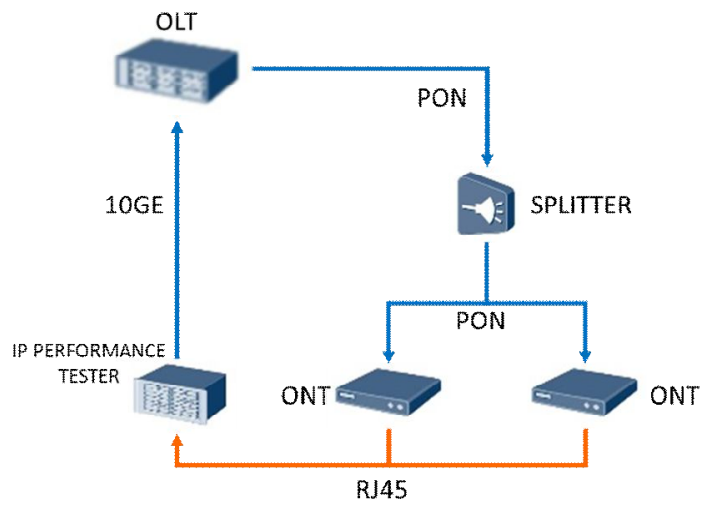

Figure 5 : Trial Test Configuration

The configuration shown in Figure 5 detailed components that are used in this research. Firstly, the OLTs connected to ONTs using splitter 1:2 and patchcord cable between the devices. In testing scenarios we utilize 4 different OLT brands. The specification for each brand of OLTs are described in tables below.

To evaluate performance of each scenarios we used IP Performance Tester device that is connected to ONTs using RJ45 cable and directly to OLTs using patchcord cable. The specification for IP Performance Tester device are described in table 1.

Table 1 : Specification of IP Performance Tester

\begin{tabular}{|c|c|}
\hline Physical Specification & $\begin{array}{l}\text { Length: } 8.45 \mathrm{in} .(214.63 \mathrm{~mm}) \\
\text { Whdth: } 5.55 \mathrm{in} .(140.97 \mathrm{~mm}) \\
\text { Height: } 1.60 \mathrm{in}(40.64 \mathrm{~mm}) \\
\text { Weight: } 1.66 \mathrm{lbs} .(0.75 \mathrm{~kg})\end{array}$ \\
\hline Bus Interfatec & USB 3.0 \\
\hline Extemal Power Supply & 49 Volts 2.0 Amps \\
\hline Optional & $\begin{array}{l}\text { 4-Port SMA Jack rrigger Board } \\
\text { (TIL InpuivOupun) }\end{array}$ \\
\hline Interfaces & $\begin{array}{l}4 \times 1 G \text { Base-X Optical OR } \\
10 / 100 \text { Loon Base-T lectrical } 2 \times \\
100 \mathrm{Mbps} \text { Base-FX Optical } \\
2 \times 2.5 \text { Gbps Electrical Interface } \\
2 \times 10 G \text { Base-SR, -LR -ER Optical } \\
\text { only } \\
\text { Single Mode or Multi Mode Fibre } \\
\text { SFP support with LC comector }\end{array}$ \\
\hline Piotocols & $\begin{array}{l}\text { IFEE } 802 \text { 3re LAN PHY complance } \\
\text { RFC } 2544 \text { complance }\end{array}$ \\
\hline
\end{tabular}




\section{RESULT AND DISCUSSION}

In OLT ' $\mathrm{N}$ ' brand GPON BW profile (2.5G / 1.2G) and TX / $\mathrm{RX}$ traffic at GE maximum line rate, average throughput: $2.43 \mathrm{Gbps}$ (DS) \& $1.21 \mathrm{Gbps}$ (US). Test at $90 \%$ BW average latency results: $21.2 \mathrm{~ms}$ (DS) \& $19.7 \mathrm{~ms}$ (US); At $80 \%$ BW results in average latency of $18.3 \mathrm{~ms}$ (DS) \& $17.1 \mathrm{~ms}$ (US); Test at $70 \%$ BW results in average latency of $3.3 \mathrm{~ms}$ (DS) \& $2.3 \mathrm{~ms}$ (US); At $60 \%$ BW results in average latency of $2.9 \mathrm{~ms}$ (DS) \& $2.5 \mathrm{~ms}$ (US). The result shows that for OLT-ONT ' $\mathrm{N}$ ' in GPON network, bandwidth allocation of more than $70 \%$ generate delay more than required by $5 \mathrm{G}$ standard of $5 \mathrm{~ms}$. Therefore it can be concluded that the optimum bandwidth allocation for this trial is $70 \%$ both downlink and uplink. The detailed result can be seen in table 2 .

Table 2 : Test Result Variance Bandwidth Capacity ONT-OLT 'N' GPON

\begin{tabular}{|c|c|c|c|c|c|c|c|c|}
\hline $\begin{array}{l}\text { Time } \\
\text { (Sec) }\end{array}$ & $\begin{array}{r}\text { DS } \\
90 \%\end{array}$ & $\begin{array}{r}\text { IIS } \\
90 \%\end{array}$ & $\begin{array}{r}\text { DS } \\
80 \%\end{array}$ & $\begin{array}{r}\text { IS } \\
80 \%\end{array}$ & $\begin{array}{r}\text { DS } \\
70 \%\end{array}$ & $\begin{array}{r}\text { IS } \\
70 \%\end{array}$ & $\begin{array}{r}\text { DS } \\
60 \%\end{array}$ & $\begin{array}{r}\text { IIS } \\
60 \%\end{array}$ \\
\hline 1 & 22,1 & 19,1 & 17,7 & 172 & 3,4 & 2,1 & 3,2 & 29 \\
\hline 2 & 10.2 & 202 & 182 & 169 & 33 & 22 & 29 & 22 \\
\hline 3 & 22.8 & 21,4 & 16,3 & 184 & 3.2 & 2.2 & 2,2 & 24 \\
\hline 4 & 187 & 17,6 & 16,2 & 17.1 & 27 & 28 & 27 & 2,2 \\
\hline 5 & 25,4 & 17,9 & 22,4 & 159 & 3,5 & 2,3 & 3,3 & 2,3 \\
\hline 6 & 21,7 & 18,2 & 109 & 11.7 & 3.2 & 2,1 & 3,2 & 3,3 \\
\hline 7 & 17,7 & 209 & 16.2 & 18,1 & 3.7 & 22 & 2,7 & 2,2 \\
\hline 8 & 20.6 & 21.3 & 18.7 & 179 & 3,5 & 2.1 & 25 & 2.6 \\
\hline 9 & 22,9 & 20.6 & 19,2 & 20,8 & 28 & 2,3 & 3,1 & 23 \\
\hline 10 & 21,2 & 19,7 & 18,3 & 17,1 & 3,3 & 2,3 & 29 & 2,5 \\
\hline
\end{tabular}

Next, we examine the latency of above and below $70 \%$ capacity namely within range of $61 \%$ to $80 \%$ in order to specify the range that is the cut-off location.

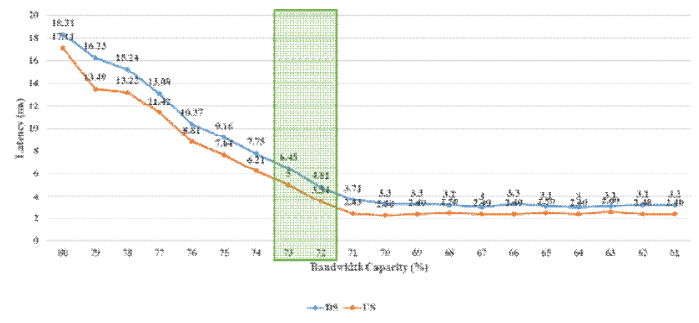

Figure 6 : Trial Result of $61 \%-80 \%$ ONT-OLT 'N' GPON

From figure 6 above we can conclude that cut-off value lies between the range of $73 \%$ to $72 \%$.

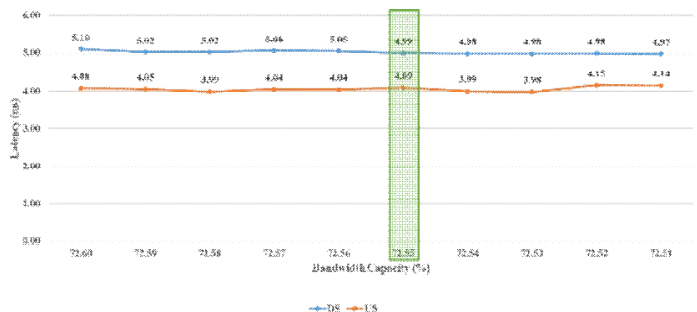

Figure 7 : Trial Result for Cut-off Value ONT-OLT 'N' GPON
Cut-off value that meet 5G latency requirement is at $72.55 \%$ bandwidth capacity with Downlink 4.99 ms and Uplink 4.09 $\mathrm{ms}$ as shown in figure 7.

For XG(S)PON BW profile (2.5G / 1.2G) and TX / RX traffic at GE maximum line rate, average throughput: $2.43 \mathrm{Gbps}$ (DS) \& $1.21 \mathrm{Gbps}$ (US). Test at $90 \% \mathrm{BW}$ average latency results: $21.2 \mathrm{~ms}$ (DS) \& $19.7 \mathrm{~ms}$ (US); At $80 \%$ BW results in average latency of $18.6 \mathrm{~ms}$ (DS) \& 7.9ms (US); Test at $70 \%$ BW results in average latency of $3.3 \mathrm{~ms}$ (DS) \& $2.3 \mathrm{~ms}$ (US); At $60 \%$ BW results in average latency of $2.2 \mathrm{~ms}$ (DS) \& $1.6 \mathrm{~ms}$ (US). The result shows that for OLT-ONT ' $\mathrm{N}$ ' in $\mathrm{XG}(\mathrm{S}) \mathrm{PON}$, bandwidth allocation of more than $70 \%$ generate delay more than required by $5 \mathrm{G}$ standard of $5 \mathrm{~ms}$. Therefore it can be concluded that the optimum bandwidth allocation for this trial is $70 \%$ both downlink and uplink. The detailed result can be seen in table 3 .

Table 3 : Test Result Variance Bandwidth Capacity ONT-OLT 'N' XG(S)PON

\begin{tabular}{|c|c|c|c|c|c|c|c|c|}
\hline $\begin{array}{l}\text { Tise } \\
(\mathrm{Sec})\end{array}$ & $\begin{array}{r}\text { DS } \\
90 \% \\
\end{array}$ & $\begin{array}{r}\text { US } \\
90 \% \\
\end{array}$ & $\begin{array}{r}\text { DS } \\
80 \% \\
\end{array}$ & $\begin{array}{r}\text { US } \\
80 \% \\
\end{array}$ & $\begin{array}{r}\text { DS } \\
70 \% \\
\end{array}$ & $\begin{array}{r}\text { US } \\
70 \% \\
\end{array}$ & $\begin{array}{r}\text { DS } \\
60 \%\end{array}$ & $\begin{array}{r}\text { US } \\
60 \% \\
\end{array}$ \\
\hline 1 & 20.2 & 8.7 & 18.8 & 8.2 & 2.2 & 1.4 & 2.2 & 14 \\
\hline 2 & 19.2 & 9.2 & 17.7 & 9.5 & 2.3 & 11 & 2.6 & 16 \\
\hline 3 & 19.8 & 10.4 & 17.1 & 7.2 & 19 & 1.2 & 19 & 1.2 \\
\hline 4 & 18.7 & 7.2 & 15.9 & 7.2 & 2.1 & 1.2 & 2.2 & 12 \\
\hline 5 & 22.4 & 73 & 287 & 73 & 18 & 2.1 & 18 & 2.1 \\
\hline 6 & 21.5 & 8.2 & 17.5 & 10.3 & 24 & 1.2 & 2.4 & 1.2 \\
\hline 7 & 17.2 & 9.3 & 17.7 & 4.3 & 1.7 & 3.2 & 2.7 & 19 \\
\hline 8 & 19.6 & 8.7 & 16.6 & 8.1 & 22 & 12 & 2.2 & 1.2 \\
\hline 9 & 18.3 & 8.6 & 17.7 & 89 & 21 & 2.1 & 2.1 & 24 \\
\hline 10 & 19.7 & 8.6 & 186 & 79 & 2.1 & 1.6 & 2.2 & 1.0 \\
\hline
\end{tabular}

Next, we examine the latency of above and below $70 \%$ capacity namely within range of $61 \%$ to $80 \%$ in order to specify the range that is the cut-off location.

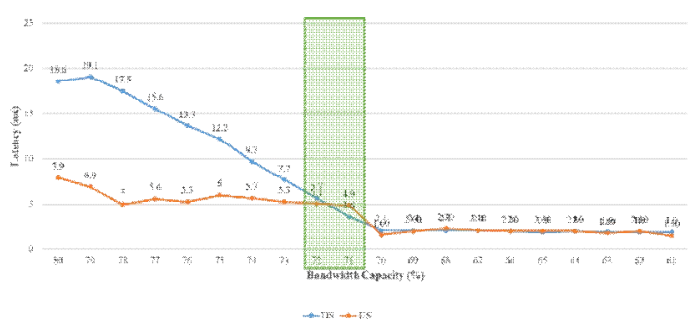

Figure 8 : Trial Result of $61 \%$ - $80 \%$ ONT-OLT 'N' XGSPON

From figure 8 above we can conclude that cut-off value lies between the range of $72 \%$ to $71 \%$.

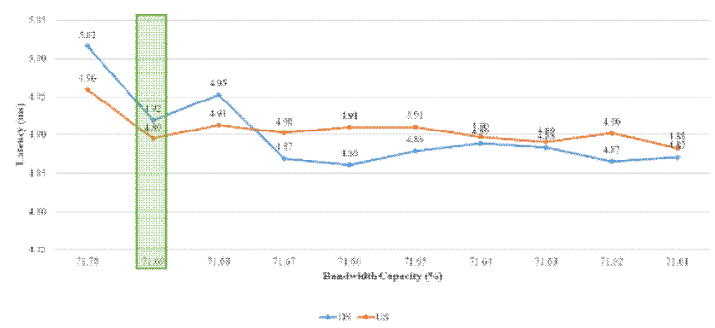

Figure 9 : Trial Result for Cut-off Value ONT-OLT 'N' XGSPON 
Cut-off value that meet $5 \mathrm{G}$ latency requirement is at $71.69 \%$ bandwidth capacity with Downlink $4.92 \mathrm{~ms}$ and Uplink 4.89 ms as shown in figure 9.

In OLT ' $\mathrm{Z}$ ' brand GPON BW profile $(2.5 \mathrm{G} / 1.2 \mathrm{G})$ and TX / $\mathrm{RX}$ traffic at GE maximum line rate, average throughput: $2.38 \mathrm{Gbps}$ (DS) \& 1.22Gbps (US); Test at $90 \% \mathrm{BW}$ average latency results: $31.4 \mathrm{~ms}$ (DS) \& $17.6 \mathrm{~ms}$ (US); At $80 \% \mathrm{BW}$ results in average latency of $28.0 \mathrm{~ms}$ (DS) \& $15.1 \mathrm{~ms}$ (US); Test on $70 \%$ BW results in average latency of $3.4 \mathrm{~ms}$ (DS) \& $2.2 \mathrm{~ms}$ (US); At $60 \% \mathrm{BW}$ results in average latency of $3.2 \mathrm{~ms}$ (DS) \& $2.5 \mathrm{~ms}$ (US). The result shows that for OLT-ONT ' $\mathrm{Z}$ ' in GPON network, bandwidth allocation of more than $70 \%$ generate delay more than required by $5 \mathrm{G}$ standard of $5 \mathrm{~ms}$. Therefore it can be concluded that the optimum bandwidth allocation for this trial is $70 \%$ both downlink and uplink. The detailed result can be seen in table 4 .

Table 4 : Test Result Variance Bandwidth Capacity ONT-OLT ' $Z$ ' GPON

\begin{tabular}{|c|c|c|c|c|c|c|c|c|}
\hline $\begin{array}{l}\text { Time } \\
\text { (Sec) }\end{array}$ & $\begin{array}{r}\text { DS } \\
\mathbf{9 0 \%}\end{array}$ & $\begin{array}{r}\text { US } \\
90 \% \\
\end{array}$ & $\begin{array}{r}\text { DS } \\
80 \% \\
\end{array}$ & $\begin{array}{r}\text { US } \\
80 \% \\
\end{array}$ & $\begin{array}{r}\text { DS } \\
70 \% \\
\end{array}$ & $\begin{array}{r}\text { US } \\
70 \% \\
\end{array}$ & $\begin{array}{r}\text { DS } \\
60 \% \\
\end{array}$ & $\begin{array}{r}\text { US } \\
60 \% \\
\end{array}$ \\
\hline 1 & 32.1 & 10.2 & 28.1 & 19.2 & 39 & $z . z$ & 3.1 & 2.2 \\
\hline 2 & 20.2 & 17.2 & 27. & 159 & 3.3 & 2.1 & 33 & 3.1 \\
\hline 3 & 32.8 & 17.4 & 28.2 & 10,5 & 3.8 & 24 & 3.6 & 24 \\
\hline 4 & 28.7 & 17.6 & 28.2 & 156 & 2.7 & 2.3 & 2.7 & 2.3 \\
\hline 5 & 32.4 & 179 & 29.6 & 15.1 & 3.5 & 23 & 3.2 & 3.3 \\
\hline 6 & 31.7 & 182 & 28. & 15.7 & 3.8 & 21 & 3.4 & 21 \\
\hline 7 & 337 & 189 & 221 & 162 & 37 & 22 & 29 & 22 \\
\hline 8 & 306 & 18.3 & 302 & 159 & 3.5 & 2.1 & 3.5 & 27 \\
\hline 9 & 312 & 16.6 & 30.1 & 161 & 2.8 & 2.3 & 28 & 2.3 \\
\hline 10 & 31.4 & 12.6 & 28.0 & 15.1 & 34 & 2.2 & 3.2 & 2.5 \\
\hline
\end{tabular}

Next, we examine the latency of above and below $70 \%$ capacity namely within range of $61 \%$ to $80 \%$ in order to specify the range that is the cut-off location.

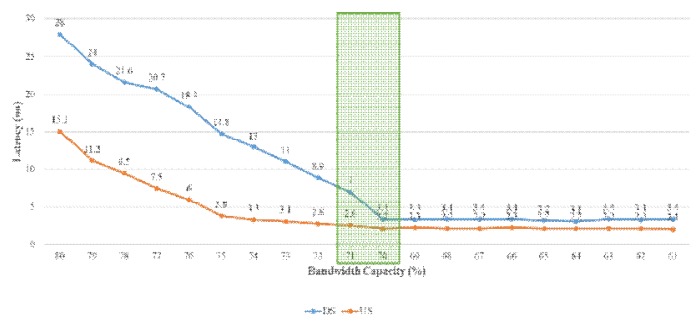

Figure 10 : Trial Result of $61 \%-80 \%$ ONT-OLT ' $Z$ ' GPON

From figure 10 above we can conclude that cut-off value lies between the range of $71 \%$ to $70 \%$.

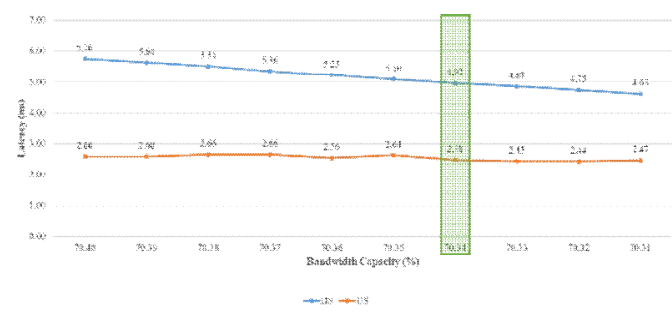

Figure 11 : Trial Result for Cut-off Value ONT-OLT ' $Z$ ' GPON
Cut-off value that meet 5G latency requirement is at $70.34 \%$ bandwidth capacity with Downlink $4.97 \mathrm{~ms}$ and Uplink 2.48 $\mathrm{ms}$ as shown in figure 11.

For XG(S)PON BW profile (10G / 10G) and TX / RX traffic at a maximum line rate of $8 \mathrm{xGE}$, average throughput: $7.86 \mathrm{Gbps}$ (DS) \& 7.84Gbps (US); Test at $90 \% \mathrm{BW}$ average latency results: $21.2 \mathrm{~ms}$ (DS) \& $10.2 \mathrm{~ms}$ (US); At $80 \% \mathrm{BW}$ results in average latency of $18.3 \mathrm{~ms}$ (DS) \& $8.4 \mathrm{~ms}$ (US); Test on $70 \% \mathrm{BW}$ results in $1.7 \mathrm{~ms}$ (DS) \& $1.3 \mathrm{~ms}$ (US) average latency; At $60 \% \mathrm{BW}$ results in average latency of $1.8 \mathrm{~ms}$ (DS) $\& 1.4 \mathrm{~ms}$ (US). The result shows that for OLT-ONT ' $\mathrm{Z}$ ' in $\mathrm{XG}(\mathrm{S}) \mathrm{PON}$, bandwidth allocation of more than $70 \%$ generate delay more than required by $5 \mathrm{G}$ standard of $5 \mathrm{~ms}$. Therefore it can be concluded that the optimum bandwidth allocation for this trial is $70 \%$ both downlink and uplink. The detailed result can be seen in table 5 .

Table 5 : Test Result Variance Bandwidth Capacity ONT-OLT ' $Z$ ' XG(S)PON

\begin{tabular}{|c|c|c|c|c|c|c|c|c|}
\hline $\begin{array}{c}\text { Time } \\
\text { (Sec) }\end{array}$ & $\begin{array}{c}\text { DS } \\
\mathbf{9 0 \%}\end{array}$ & $\begin{array}{r}\text { IS } \\
\mathbf{9 0 \%}\end{array}$ & $\begin{array}{r}\text { DS } \\
\mathbf{8 0 \%}\end{array}$ & $\begin{array}{c}\text { IS } \\
\mathbf{8 0 \%}\end{array}$ & $\begin{array}{r}\text { DS } \\
\mathbf{7 0 \%}\end{array}$ & $\begin{array}{r}\text { IS } \\
\mathbf{7 0 \%}\end{array}$ & $\begin{array}{r}\text { DS } \\
\mathbf{6 0 \%}\end{array}$ & $\begin{array}{r}\text { IS } \\
\mathbf{6 0 \%}\end{array}$ \\
\hline $\mathbf{1}$ & 20.2 & 10.7 & 17.2 & 7.7 & 1.2 & 1.4 & 1.7 & 1.4 \\
\hline 2 & 21.2 & 10.2 & 19.5 & 10.8 & 1.7 & 1.1 & 1.7 & 1.1 \\
\hline 3 & 20.8 & 10.4 & 18.2 & 8.8 & 1.9 & 1.2 & 1.9 & 1.8 \\
\hline 4 & 22.7 & 10.2 & 21.9 & 9.3 & 1.1 & 1.2 & 1.1 & 1.2 \\
\hline 5 & 22.4 & 11.3 & 15.2 & 8.2 & 1.8 & 1.1 & 1.8 & 1.1 \\
\hline 6 & 21.5 & 9.2 & 19.8 & 5.2 & 1.4 & 1.2 & 2.4 & 1.2 \\
\hline 7 & 20.2 & 9.3 & 16.1 & 7.3 & 1.7 & 1.1 & 1.7 & 1.7 \\
\hline 8 & 21.6 & 10.7 & 19.2 & 9.2 & 2.2 & 1.2 & 2.2 & 1.2 \\
\hline 9 & 20.3 & 2.6 & 17.7 & 9.5 & 2.1 & 1.9 & 2.1 & 1.9 \\
\hline 10 & 21.2 & 10.2 & 18.3 & 8.4 & 1.7 & 1.3 & 1.8 & 1.4 \\
\hline
\end{tabular}

Next, we examine the latency of above and below $70 \%$ capacity namely within range of $61 \%$ to $80 \%$ in order to specify the range that is the cut-off location.

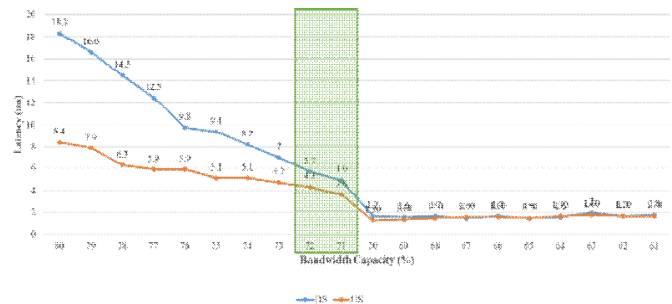

Figure 12 : Trial Result of $61 \%-80 \%$ ONT-OLT ' $Z$ ' XGSPON

From figure 12 above we can conclude that cut-off value lies between the range of $72 \%$ to $71 \%$.

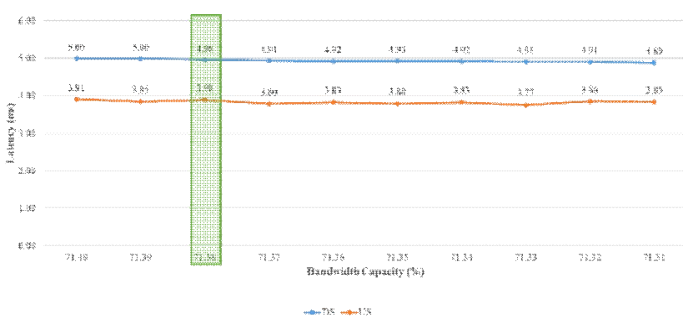

Figure 13 : Trial Result for Cut-off Value ONT-OLT ' $Z$ ' XGSPON 
Cut-off value that meet $5 \mathrm{G}$ latency requirement is at $71.38 \%$ bandwidth capacity with Downlink 4.96 ms and Uplink 3.90 $\mathrm{ms}$ as shown in figure 13 .

In OLT 'H' brand GPON BW profile (2.5G / 1.2G) and TX / $\mathrm{RX}$ traffic at GE maximum line rate, average throughput: $2.35 \mathrm{Gbps}$ (DS) \& 1.21Gbps (US); Test at $90 \% \mathrm{BW}$ average latency results: $22.3 \mathrm{~ms}$ (DS) \& $11.7 \mathrm{~ms}$ (US); At $80 \% \mathrm{BW}$ results in average latency of $20.4 \mathrm{~ms}$ (DS) \& $10.9 \mathrm{~ms}$ (US); Test on $70 \%$ BW results in $1.7 \mathrm{~ms}$ (DS) \& $1.2 \mathrm{~ms}$ (US) average latency; At $60 \% \mathrm{BW}$ results in average latency of $1.6 \mathrm{~ms}$ (DS) $\& 1.2 \mathrm{~ms}$ (US). The result shows that for OLT-ONT ' $\mathrm{H}$ ' in GPON network bandwidth allocation of more than $70 \%$ generate delay more than required by $5 \mathrm{G}$ standard of $5 \mathrm{~ms}$. Therefore it can be concluded that the optimum bandwidth allocation for this trial is $70 \%$ both downlink and uplink. The detailed result can be seen in table 6 .

Table 6 : Test Result Variance Bandwidth Capacity ONT-OLT 'H' GPON

\begin{tabular}{|c|c|c|c|c|c|c|c|c|}
\hline $\begin{array}{c}\text { Time } \\
\text { (Sec) }\end{array}$ & $\begin{array}{c}\text { DS } \\
90 \%\end{array}$ & $\begin{array}{r}\text { US } \\
90 \%\end{array}$ & $\begin{array}{r}\text { DS } \\
80 \%\end{array}$ & $\begin{array}{r}\text { US } \\
80 \%\end{array}$ & $\begin{array}{r}\text { DS } \\
70 \%\end{array}$ & $\begin{array}{r}\text { US } \\
70 \%\end{array}$ & $\begin{array}{r}\text { DS } \\
60 \%\end{array}$ & $\begin{array}{r}\text { US } \\
60 \%\end{array}$ \\
\hline 1 & 22.1 & 11.2 & 20.2 & 10.1 & 1.9 & 1.2 & 1.5 & 1.2 \\
\hline 2 & 22.2 & 11.2 & 20.1 & 10.3 & 1.3 & 1.1 & 1.3 & 1.1 \\
\hline 3 & 23.8 & 12.4 & 22.1 & 11 & 1.8 & 1.4 & 1.5 & 1.3 \\
\hline 4 & 22.7 & 11.6 & 20.3 & 10.2 & 1.7 & 1.3 & 1.7 & 1.3 \\
\hline 5 & 22.4 & 11.9 & 20.4 & 99 & 1.5 & 1.3 & 15 & 1.3 \\
\hline 6 & 21.7 & 12.2 & 17.1 & 11.2 & 1.8 & 1.1 & 1.6 & 1.1 \\
\hline 7 & 22.7 & 11.9 & 21.7 & 15.9 & 1.3 & 1.2 & 1.7 & 1.2 \\
\hline 8 & 21.6 & 11.3 & 21.8 & 10.1 & 1.5 & 1.1 & 2.1 & 1.1 \\
\hline 9 & 21.2 & 11.6 & 20.3 & 9.6 & 1.8 & 1.3 & 1.8 & 1.3 \\
\hline 10 & 22.3 & 11.7 & 20.4 & 10.9 & 1.7 & 1.2 & 1.6 & 1.2 \\
\hline
\end{tabular}

Next, we examine the latency of above and below $70 \%$ capacity namely within range of $61 \%$ to $80 \%$ in order to specify the range that is the cut-off location.

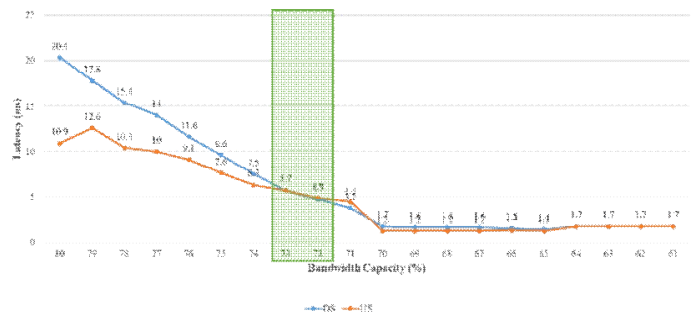

Figure 14 : Trial Result of $61 \%-80 \%$ ONT-OLT 'H' GPON

From figure 14 above we can conclude that cut-off value lies between the range of $73 \%$ to $72 \%$.

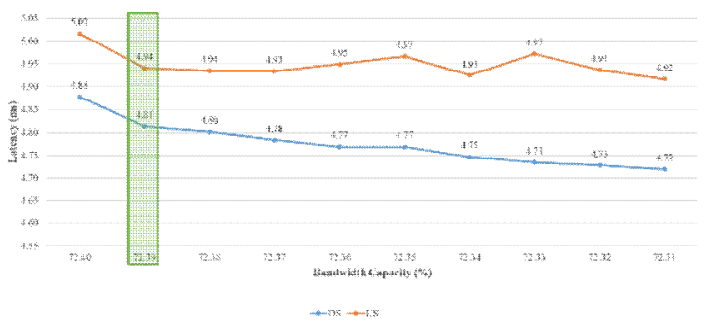

Figure 15 : Trial Result for Cut-off Value ONT-OLT 'H' GPON
Cut-off value that meet 5G latency requirement is at $72.39 \%$ bandwidth capacity with Downlink $4.81 \mathrm{~ms}$ and Uplink 4.94 $\mathrm{ms}$ as shown in figure 15.

For XG(S)PON BW profile (10G / 10G) and TX / RX traffic at a maximum line rate of $10 \mathrm{GE}$, average throughput: 9,680Gbps (DS) \& 8.59Gbps (US); Test at 90\% BW average latency results: $17.5 \mathrm{~ms}$ (DS) \& 9.3ms (US); At $80 \% \mathrm{BW}$ results in average latency of $14.6 \mathrm{~ms}$ (DS) \& $8.4 \mathrm{~ms}$ (US); Test at $70 \% \mathrm{BW}$ results on average latency of $1.4 \mathrm{~ms}$ (DS) \& $1.3 \mathrm{~ms}$ (US); At $60 \%$ BW results in average latency of $1.5 \mathrm{~ms}$ (DS) \& $1.3 \mathrm{~ms}$ (US). The result shows that for OLT-ONT ' $\mathrm{H}$ ' in $\mathrm{XG}(\mathrm{S}) \mathrm{PON}$, bandwidth allocation of more than $70 \%$ generate delay more than required by $5 \mathrm{G}$ standard of $5 \mathrm{~ms}$. Therefore it can be concluded that the optimum bandwidth allocation for this trial is $70 \%$ both downlink and uplink. The detailed result can be seen in table 7 .

Table 7 : Test Result Variance Bandwidth Capacity ONT-OLT 'H' XG(S)PON

\begin{tabular}{|c|c|c|c|c|c|c|c|c|}
\hline $\begin{array}{l}\text { Time } \\
\text { (Sec) }\end{array}$ & $\begin{array}{c}\text { DS } \\
\mathbf{9 0 \%}\end{array}$ & $\begin{array}{r}\text { US } \\
90 \%\end{array}$ & $\begin{array}{r}\text { DS } \\
80 \%\end{array}$ & $\begin{array}{r}\text { US } \\
80 \%\end{array}$ & $\begin{array}{r}\text { DS } \\
70 \%\end{array}$ & $\begin{array}{r}\text { US } \\
70 \%\end{array}$ & $\begin{array}{r}\text { DS } \\
60 \%\end{array}$ & $\begin{array}{r}\text { US } \\
60 \%\end{array}$ \\
\hline 1 & 17.2 & 9.7 & 152 & 85 & 1.2 & 1,4 & 12 & 1.4 \\
\hline 2 & 18.2 & 9.2 & 15.4 & 8.2 & 1.1 & 1.1 & 1.1 & 1.1 \\
\hline 3 & 178 & 94 & 10,8 & 8.4 & 1,3 & 12 & 1.3 & 1,2 \\
\hline 4 & 177 & 0.2 & 14.7 & 7.5 & 1.1 & 1.2 & 1.1 & 1.2 \\
\hline 5 & 174 & 9.3 & 152 & 7.7 & 1.3 & 1.3 & 13 & 1.3 \\
\hline 6 & 16.5 & 9.2 & 145 & 8.2 & 14 & 1.2 & 2.2 & 19 \\
\hline 7 & 17.2 & 9.3 & 13.7 & 8.3 & 12 & 1.1 & 1.2 & 1.1 \\
\hline 8 & 17.6 & 8.3 & 156 & 10.7 & 2.1 & 1.2 & 2.1 & 12 \\
\hline 9 & 183 & 96 & 161 & 83 & 22 & 16 & 2.2 & 1.6 \\
\hline 10 & 17.5 & 9.3 & 14.6 & 8.4 & 1.4 & 1.3 & 1.5 & 1.3 \\
\hline
\end{tabular}

Next, we examine the latency of above and below $70 \%$ capacity namely within range of $61 \%$ to $80 \%$ in order to specify the range that is the cut-off location.

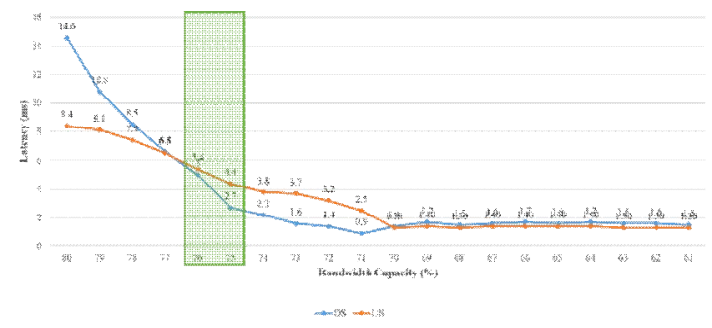

Figure 16 : Trial Result of $61 \%-80 \%$ ONT-OLT ' $\mathrm{H}$ ' XGSPON

From figure 16 above we can conclude that cut-off value lies between the range of $76 \%$ to $75 \%$.

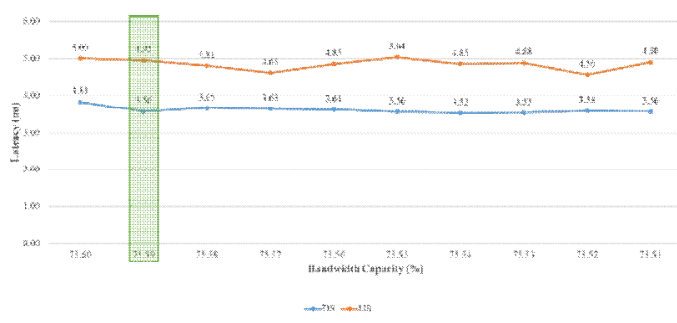

Figure 17 : Trial Result for Cut-off Value ONT-OLT ' $\mathrm{H}$ ' XGSPON 
Cut-off value that meet $5 \mathrm{G}$ latency requirement is at $75.59 \%$ bandwidth capacity with Downlink $3.56 \mathrm{~ms}$ and Uplink 4.95 $\mathrm{ms}$ as shown in figure 17.

In OLT ' $F$ ' brand GPON BW profile $(2.5 \mathrm{G} / 1.2 \mathrm{G})$ and TX / $\mathrm{RX}$ traffic at GE maximum line rate, average throughput: $2.37 \mathrm{Gbps}$ (DS) \& 1.23Gbps (US); Test at $90 \% \mathrm{BW}$ average latency results: $12.3 \mathrm{~ms}$ (DS) \& $13.4 \mathrm{~ms}$ (US); At $80 \% \mathrm{BW}$ results in average latency of $11.4 \mathrm{~ms}$ (DS) \& $13.4 \mathrm{~ms}$ (US); Test at $70 \% \mathrm{BW}$ results in average latency of $1.6 \mathrm{~ms}$ (DS) \& $1.4 \mathrm{~ms}$ (US); At $60 \% \mathrm{BW}$ results in average latency of $1.5 \mathrm{~ms}$ (DS) \& $1.3 \mathrm{~ms}$ (US). The result shows that for OLT-ONT ' $\mathrm{F}$ ' in GPON network, bandwidth allocation of more than $70 \%$ generate delay more than required by $5 \mathrm{G}$ standard of $5 \mathrm{~ms}$. Therefore it can be concluded that the optimum bandwidth allocation for this trial is $70 \%$ both downlink and uplink. The detailed result can be seen in table 8 .

Table 8 : Test Result Variance Bandwidth Capacity ONT-OLT 'F' GPON

\begin{tabular}{|c|c|c|c|c|c|c|c|c|}
\hline $\begin{array}{c}\text { Time } \\
(\mathbf{S e c})\end{array}$ & $\begin{array}{c}\text { DS } \\
\mathbf{9 0 \%}\end{array}$ & $\begin{array}{r}\text { US } \\
\mathbf{9 0 \%}\end{array}$ & $\begin{array}{r}\text { DS } \\
80 \%\end{array}$ & $\begin{array}{r}\text { US } \\
\mathbf{8 0} \%\end{array}$ & $\begin{array}{r}\text { DS } \\
\mathbf{7 0} \%\end{array}$ & $\begin{array}{r}\text { US } \\
70 \%\end{array}$ & $\begin{array}{r}\text { DS } \\
\mathbf{6 0 \%}\end{array}$ & $\begin{array}{r}\text { US } \\
60 \%\end{array}$ \\
\hline 1 & 12.1 & 13.2 & 11.8 & 12.5 & 1.9 & 1.2 & 1.7 & 1.2 \\
\hline 2 & 12.2 & 13.2 & 12.1 & 12.8 & 1.3 & 1.1 & 1.3 & 1.1 \\
\hline 3 & 13.8 & 13.4 & 12.8 & 12.6 & 1.8 & 1.8 & 1.6 & 1.6 \\
\hline 4 & 12.7 & 13.6 & 12.2 & 13.2 & 1.7 & 1.3 & 1.5 & 1.3 \\
\hline 5 & 12.4 & 13.2 & 7.7 & 12.4 & 1.5 & 1.5 & 1.5 & 1.2 \\
\hline 6 & 11.7 & 13.2 & 11.3 & 12.7 & 1.2 & 1.4 & 1.2 & 1.1 \\
\hline 7 & 12.7 & 14.1 & 11.9 & 13.2 & 1.3 & 1.2 & 1.5 & 1.2 \\
\hline 8 & 11.6 & 13.3 & 11.6 & 17.6 & 1.5 & 2.1 & 1.5 & 1.7 \\
\hline 9 & 11.2 & 13.2 & 11.2 & 13.2 & 1.8 & 1.3 & 1.7 & 1.3 \\
\hline 10 & 12.3 & 13.4 & 11.4 & 13.4 & 1.6 & 1.4 & 1.5 & 1.3 \\
\hline
\end{tabular}

Next, we examine the latency of above and below $70 \%$ capacity namely within range of $61 \%$ to $80 \%$ in order to specify the range that is the cut-off location.

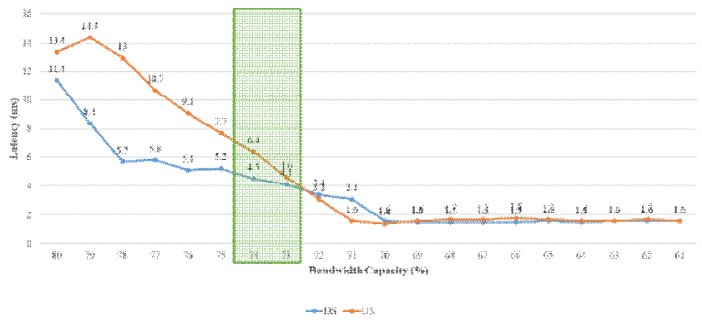

Figure 18 : Trial Result of $61 \%$ - 80\% ONT-OLT 'F' GPON

From figure 18 above we can conclude that cut-off value lies between the range of $74 \%$ to $73 \%$.

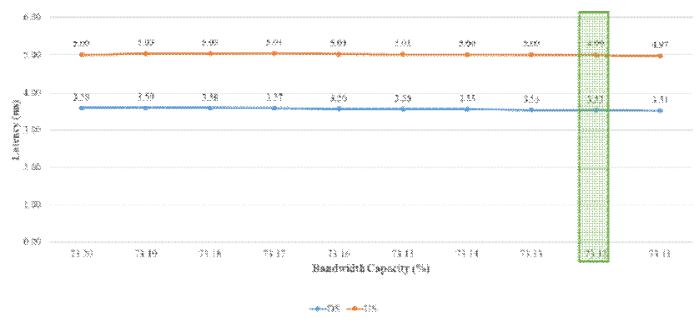

Figure 19 : Trial Result for Cut-off Value ONT-OLT 'F' GPON
Cut-off value that meet $5 \mathrm{G}$ latency requirement is at $73.12 \%$ bandwidth capacity with Downlink $3.53 \mathrm{~ms}$ and Uplink 4.99 ms as shown in figure 19.

For XG(S)PON BW profile (10G / 10G) and TX / RX traffic at a maximum line rate of $8 \mathrm{xGE}$, average throughput: $7.86 \mathrm{Gbps}$ (DS) \& 7.84Gbps (US); Test at $90 \% \mathrm{BW}$ average latency results: $19.5 \mathrm{~ms}$ (DS) \& $9.5 \mathrm{~ms}$ (US); Test at $90 \% \mathrm{BW}$ results in average latency of $1.5 \mathrm{~ms}$ (DS) \& $1.3 \mathrm{~ms}$ (US); At $80 \% \mathrm{BW}$ results in average latency of $17.4 \mathrm{~ms}$ (DS) \& $8.9 \mathrm{~ms}$ (US); Test at $70 \% \mathrm{BW}$ results in average latency of $1.5 \mathrm{~ms}$ (DS) \& $1.3 \mathrm{~ms}$ (US); At $60 \% \mathrm{BW}$ results in average latency of $1.6 \mathrm{~ms}$ (DS) \& $1.4 \mathrm{~ms}$ (US). The result shows that for OLT-ONT 'F' in XG(S)PON network, bandwidth allocation of more than $70 \%$ generate delay more than required by $5 \mathrm{G}$ standard of $5 \mathrm{~ms}$. Therefore it can be concluded that the optimum bandwidth allocation for this trial is $70 \%$ both downlink and uplink. The detailed result can be seen in table 9 .

Table 9 : Test Result Variance Bandwidth Capacity ONT-OLT 'F' XG(S)PON

\begin{tabular}{|c|c|c|c|c|c|c|c|c|}
\hline $\begin{array}{r}\text { Time } \\
\text { (Sec) }\end{array}$ & $\begin{array}{r}\text { DS } \\
\mathbf{9 0 \%}\end{array}$ & $\begin{array}{r}\text { IS } \\
90 \%\end{array}$ & $\begin{array}{r}\text { DS } \\
80 \%\end{array}$ & $\begin{array}{r}\text { IS } \\
80 \%\end{array}$ & $\begin{array}{r}\text { DS } \\
\mathbf{7 0 \%}\end{array}$ & $\begin{array}{r}\text { IS } \\
70 \%\end{array}$ & $\begin{array}{r}\text { DS } \\
60 \%\end{array}$ & $\begin{array}{r}\text { IS } \\
60 \%\end{array}$ \\
\hline $\mathbf{1}$ & 19.2 & 9.7 & 17.4 & 9.1 & 1.2 & 1.4 & 1.2 & 1.4 \\
\hline 2 & 18.2 & 10.2 & 16.2 & 8.2 & 1.6 & 1.3 & 1.6 & 1.3 \\
\hline 3 & 19.8 & 9.4 & 17.5 & 11.1 & 1.3 & 1.2 & 1.3 & 1.2 \\
\hline 4 & 19.7 & 9.2 & 17.7 & 9.2 & 1.4 & 1.5 & 2.1 & 2.2 \\
\hline $\mathbf{5}$ & 19.4 & 9.3 & 15.1 & 9.3 & 1.3 & 1.3 & 1.3 & 1.3 \\
\hline 6 & 19.5 & 10.1 & 17.9 & 8.9 & 1.4 & 1.2 & 1.4 & 1.2 \\
\hline 7 & 20.2 & 9.3 & 18.5 & 8.3 & 1.2 & 1.2 & 1.2 & 1.2 \\
\hline 8 & 19.6 & 8.7 & 18.1 & 7.7 & 2.1 & 1.2 & 2.1 & 1.2 \\
\hline 9 & 20.3 & 9.3 & 18.5 & 8.2 & 2.2 & 1.5 & 2.2 & 1.2 \\
\hline 10 & 19.5 & 9.5 & 17.4 & 8.9 & 1.5 & 1.3 & 1.6 & 1.4 \\
\hline
\end{tabular}

Next, we examine the latency of above and below $70 \%$ capacity namely within range of $61 \%$ to $80 \%$ in order to specify the range that is the cut-off location.

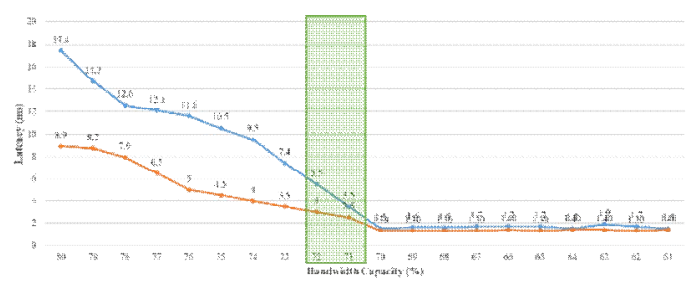

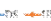

Figure 20 : Trial Result of $61 \%-80 \%$ ONT-OLT 'F' XGSPON

From figure 20 above we can conclude that cut-off value lies between the range of $72 \%$ to $71 \%$.

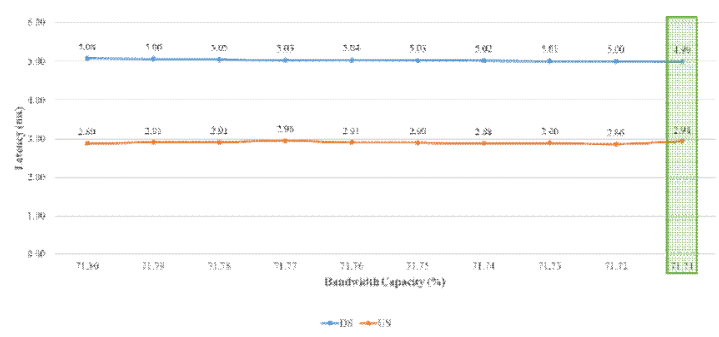

Figure 21 : Trial Result for Cut-off Value ONT-OLT 'F' XGSPON 
Cut-off value that meet $5 \mathrm{G}$ latency requirement is at $71.71 \%$ bandwidth capacity with Downlink $4.99 \mathrm{~ms}$ and Uplink 2.94 $\mathrm{ms}$ as shown in figure 21 .

\section{CONCLUSION}

Based on test result above, percentage of utilization traffic per BW profile will contribute to delay performance, for more than $100 \%$ will add significant delay. Refer to simulation result for mean access delay with variable on load data \& type of DBA in all brands of OLT and ONT, starting from $70 \%$ load traffic will increase significant delay. This result similar with test result using PON node access. $70 \%$ traffic load as a threshold for increase bandwidth to perform good delay performance. In order to meet the $5 \mathrm{G}$ latency requirement of $5 \mathrm{~ms}$, the most suitable capacity allocation is $70 \%$ with average latency combined of upstream and downlink is $2.8 \mathrm{~ms}$. Furthermore, the average optimum bandwidth capacity is $72.10 \%$ and $72.59 \%$ for GPON and XGSPON respectively.

\section{ACKNOWLEDGEMENT}

The research in this paper was supported by Universitas

Indonesia, under PITTA Grant No.

2446/UN2.R3.1/HKP.05.00/2018

\section{REFERENCES}

1. H. Chen, et al. Cost-minimized design for twdm-pon-based $5 g$ mobile backhaul networks. Optical Society of America Journal, 2016.

2. X. Ge, et al. 5 g wireless backhaul networks: challenges and research advances. IEEE Networks, 2014.

3. T. Jun, et al. Optical access network technology for $5 g$ wireless front/backhaul network, OECC, 2016.

4. X. Liu, et al. Emerging optical access network technologies for $5 \mathrm{~g}$ wireless (invited). Optical Society of America Journal, 2016.

5. J. Sung. et al. Cost-effective mobile backhaul network using existing odn of pons for the $5 g$ wireless systems. IEEE Photonics Society, 2015.

6. K. Triningsih. et al. Multipartition dba method on gpon. IEEE, 2017.

7. J. S. Vardakas. et al. Towards high capacity and low latency backhauling in 5g: the $5 g$ step-fwd vision. ICTON, 2017.

8. G. Xiaohu. et al. $5 g$ wireless backhaul networks: challenges and research advances. IEEE Network, vol. 28 , no. 6, 2014. 